\title{
Nuevas tendencias de la inmigración en Tenerife
}

Elaborado por Daniel Buraschi y Vicente Manuel Zapata Hernández

La reactivación de la inmigración en Tenerife en los últimos años presenta algunas novedades con respecto a etapas anteriores, como son la intensificación de las afluencias de origen venezolano, cubano e italiano, frente a la reducción de flujos tradicionales como el alemán - británico. La mayor repercusión de las motivaciones laborales, frente a las residenciales por ejemplo, hace que se refuerce el asentamiento de los nuevos habitantes en la franja meridional de la isla, particularmente en el arco Suroeste. También influye en la diversificación de la población residente y en la conformación de más localidades con un mayor componente multicultural.

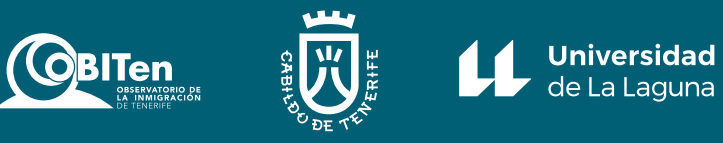




\section{Introducción}

Tras el impasse de la crisis económica se ha reactivado la afluencia exterior en Tenerife, pero con algunas novedades en relación con la etapa anterior, en el marco de una dinámica bastante influenciada por el contexto general y particularmente vinculada a las circunstancias de los territorios que aportan más efectivos a la población de la Isla en los últimos años. Procedencias que vienen atravesando por situaciones favorables a la emigración, tanto de orden socioeconómico como institucional y político, bastante prolongadas en el tiempo en determinados casos.

En este sentido, cabe señalar el hecho de que los procesos migratorios suelen tener una manifestación variable en el tiempo, puesto que son fruto de la confluencia de un importante conjunto de factores y motivaciones que asimismo pueden cambiar, ya que, en última instancia, dependen de las decisiones de personas, familias y grupos humanos que valoran múltiples aspectos antes de migrar. Y también consideran hacia dónde se dirigen y orientan su asentamiento, siendo entonces relevante el papel que desempeñan aspectos como los precedentes migratorios de las áreas de emigración, la información y los recursos disponibles, la posibilidad de encontrar algún tipo de ayuda en destino, etc.

En determinados casos son más fuertes las causas que obligan a las personas a abandonar sus lugares de origen, que la incertidumbre que puede ocasionar su instalación en un territorio que ofrezca especiales dificultades de cara al asentamiento y a la actividad de muchos de los nuevos habitantes, en particular de aquellos que ofrecen una situación más precaria. Ahí adquieren enorme importancia las comunidades previamente instaladas, que reciben y orientan a las personas recién llegadas, e incluso, pueden darles soporte durante la etapa inicial de presencia en las áreas de inmigración.

Y en ese contexto de reactivación de la movilidad exterior, crece la población de Tenerife nuevamente desde 2016, superando en 2019 el máximo alcanzado en 2011 por encima de los 900 mil habitantes. Y la mayor o menor incidencia de las distintas corrientes de inmigración en unos lugares u otros de la geografía insular provoca cambios importantes, por ejemplo en la distribución de la población, reforzando en esta oportunidad la vertiente meridional y su prolongación hacia el espacio metropolitano, en lo que también influyen las motivaciones, necesidades y aspiraciones de las personas que se desplazan.

En este trabajo nos centramos en el estudio más detallado de las dos comunidades de origen extranjero más numerosas en fechas recientes, procedentes de Venezuela e Italia, que suman 61.810 habitantes en 2018, exactamente un tercio de la población foránea asentada en Tenerife. $Y$ sus tendencias y los indicios existentes apuntan a la continuidad de la dinámica de crecimiento observada en la actualidad, cuando Tenerife concentra el $72,9 \%$ de los venezolanos y el 32,9\% de los italianos en el marco regional canario, donde suponen el $2,7 \%$ y $1,7 \%$, respectivamente, de su población total.

Se incluyen también en el estudio las tres siguientes procedencias según el número de sus efectivos, entre las que destacan dos europeas de asentamiento tradicional, pero que han perdido peso recientemente en el conjunto, Reino Unido y Alemania, junto al colectivo cubano, cuya presencia se mantiene en el tiempo incrementando sus efectivos en los últimos años. Si agrupamos las cinco rondan los 100 mil habitantes en 2018, algo más de la mitad de la población nacida en otros países empadronada en Tenerife.

El texto resultante del análisis se organiza en varios apartados, comenzando por el que recoge una semblanza general de la más reciente manifestación de la inmigración en Te- 
nerife, caracterizando luego sus principales perfiles sociodemográficos y pautas de asentamiento, para entrar, finalmente, en el estudio más detallado de las procedencias venezolana e italiana. Para ello se ha contado con distinta información estadística, junto a la realización de una encuesta online con el objetivo de profundizar en la identificación de las motivaciones de los desplazamientos y en su desarrollo.

\section{Principales tendencias de la inmigración en Tenerife}

La inmigración de origen extranjero ha seguido siendo el factor clave del crecimiento de la población de Tenerife durante el periodo de tiempo que ya se lleva consumido del siglo XXI. Su aportación ronda las tres cuartas partes del aumento experimentado desde 2001, que se cifra en 160.637 efectivos hasta 2018, con una tasa anual de crecimiento acumulado de $1,16 \%$. Esto ha hecho, por ejemplo, que Tenerife siga siendo la isla más poblada de Canarias, con el 42,5\% de su empadronamiento en la última fecha citada, y que, además, siga la senda de la diversificación de su base social por la llegada de nuevos habitantes procedentes de un amplio número de países.

Esa dinámica de sostenido crecimiento poblacional se vio afectada, sin embargo, por el amplio lapso de crisis general que se proyecta en la demografía de la Isla desde el año 2011 y hasta 2016, cuando Tenerife pierde efectivos durante casi un quinquenio, coincidiendo con exiguos aportes exteriores, e incluso, con balances migratorios desfavorables. Aun así, el pulso demográfico se recupera y la curva de crecimiento remonta hasta situar las cifras de población total y de origen extranjero casi al nivel de las más elevadas registradas hasta la fecha. Superando nuevamente los 900 mil habitantes en 2018, Tenerife registra 186.354 efectivos nacidos en otros países, el 20,6\% de su empadronamiento, con una leve diferencia a favor de las mujeres $(51,4 \%)$, resaltando un mayor protagonismo femenino ahora que a comienzos de siglo en cuanto a la proyección de la inmigración.

La población de origen extranjero casi se ha duplicado en lo que va de siglo, mostrando una intensidad apreciable $(5,94 \%$ anual), mayor en mujeres que en hombres, y además, distinta según procedencias. Esto ha ocasionado un nuevo balance en lo que respecta al peso de los orígenes continentales, asumiendo ahora el protagonismo la corriente americana, que ha logrado conformar un amplio conjunto de habitantes que supera la mitad del total de efectivos registrado: 50,7\% en 2018, a un ritmo anual del 7,44\% desde 2011.

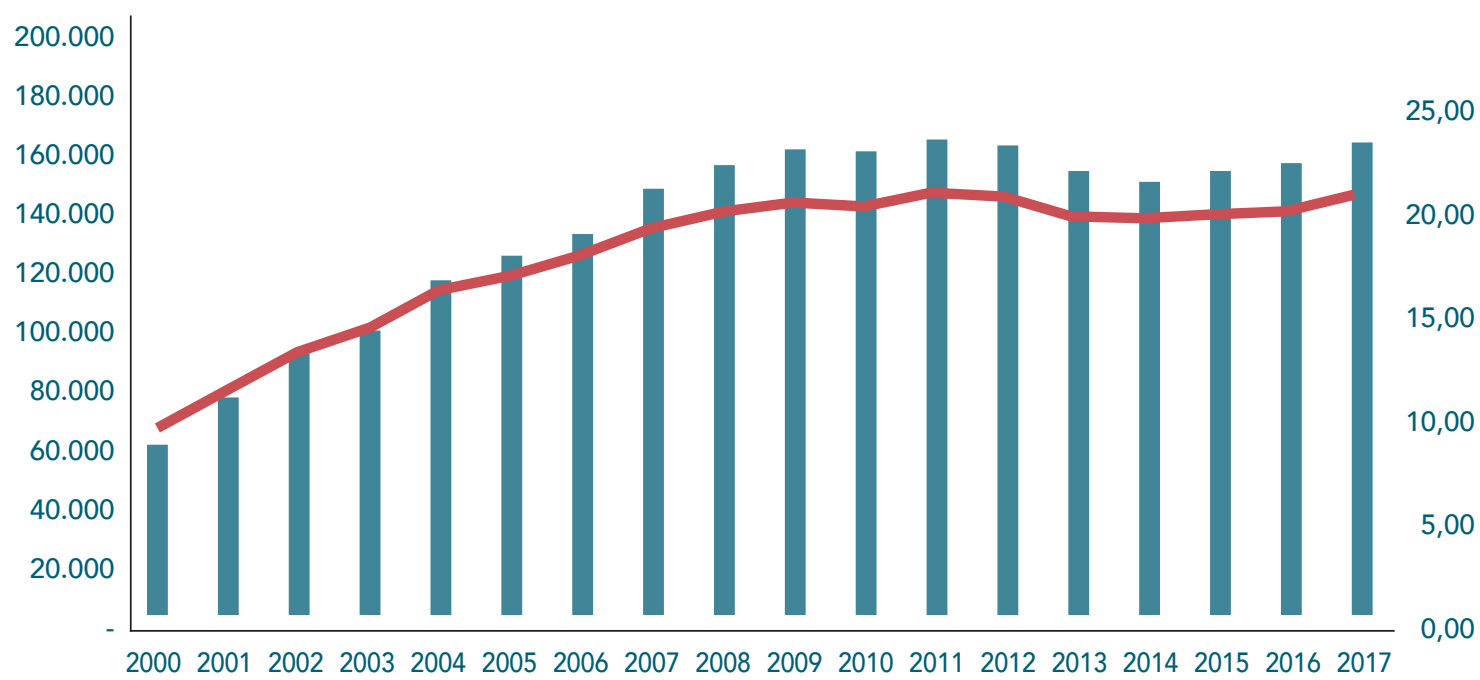

Gráfico 1

Evolución y peso demográfico de la población de origen extranjero en Tenerife entre 2001 y 2018.

\section{Fuente}

Padrón Municipal de Habitantes, ISTAC.

Elaboración propia. 
El empuje venezolano ha sido crucial en los últimos años, pero, también, los incrementos que han observado orígenes como Cuba, Colombia, Argentina, Uruguay o Ecuador. Venezuela es con diferencia la procedencia internacional más importante en Tenerife: 42.586 habitantes en 2018 , el $22,9 \%$ de la población de origen extranjero y casi el $5 \%$ de la población insular. Pese a estas cifras, la comunidad venezolana ha perdido cierto peso en el conjunto exterior con respecto a 2001, puesto que la diversificación a través del ascenso de otras afluencias también ha sido importante.

El protagonismo de la comunidad europea se ha debilitado bastante, si bien, el reciente despunte de las personas de origen italiano ha frenado una importante merma de su presencia en la Isla a partir del escaso crecimiento de británicos y la inesperada reducción de alemanes: el primer colectivo solo aporta 2.611 nuevos efectivos entre 2001 y 2018; el segundo se reduce en 850 en el mismo periodo. Distintos factores pueden explicar esta reorientación de los pesos poblacionales, relacionados, entre otros, con la pérdida natural de efectivos comunitarios que se retiraron en Tenerife siendo ya mayores, así como las nuevas preferencias de las personas que se está jubilando en estos momentos, tal vez menos propensas a la adquisición de una vivienda en el extranjero. Y esta situación puede intensificarse en el futuro al observar las estructuras demográficas de ambas comunidades, altamente envejecidas, junto a los inciertos escenarios relacionados con la estancia de británicos fuera del Reino Unido (Brexit) o la evolución de la economía alemana.

Gráfico 2

Evolución de los cinco orígenes nacionales con más efectivos en Tenerife entre 2001 y 2018.

Fuente

Padrón Municipal de Habitantes, ISTAC. Elaboración propia. 31 de mayo de 2019.

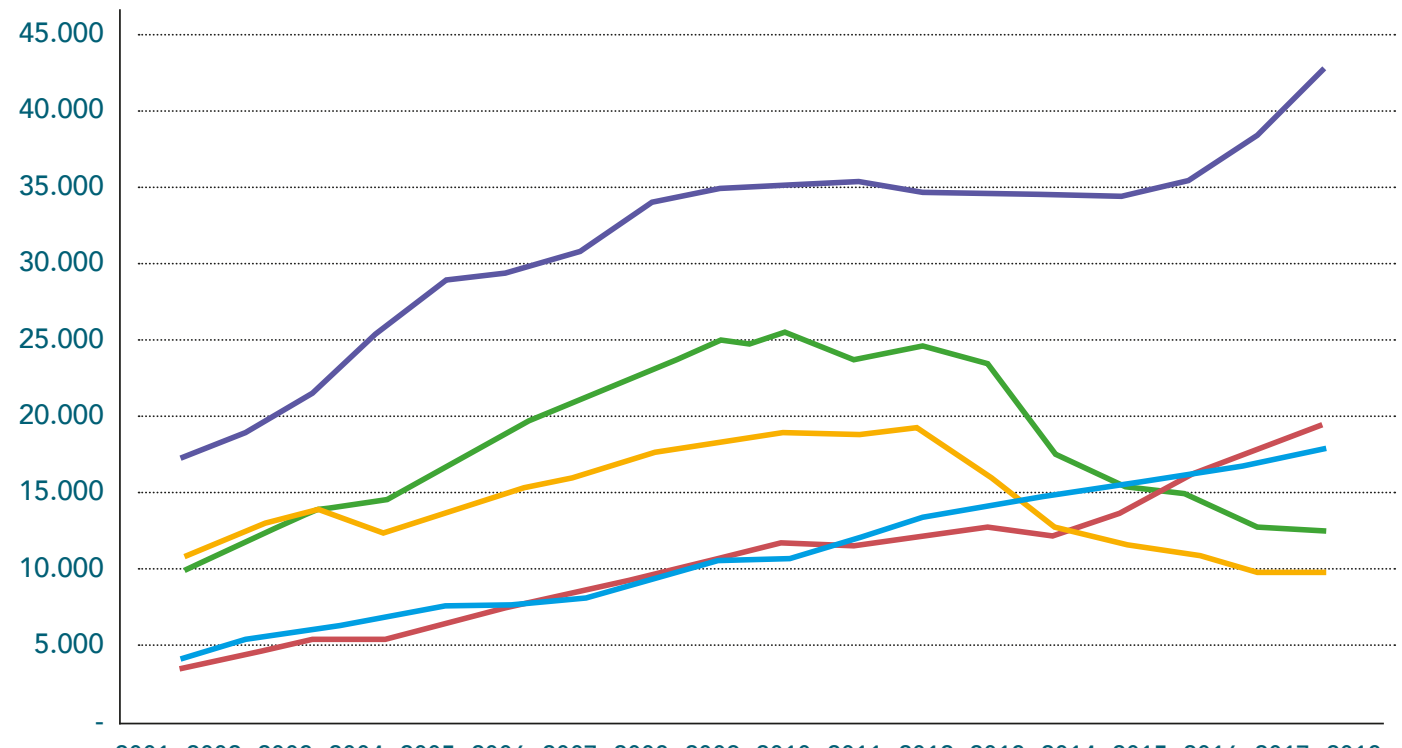

200120022003200420052006200720082009201020112012201320142015201620172018

$$
\text { Venezuela }=\text { Italia Cuba Reino Unido } \quad \text { Alemania }
$$

En este mano a mano entre los flujos europeo y americano, las afluencias africana y asiática continúan siendo minoritarias, aun registrando importantes ascensos del número de sus efectivos y la emergencia de procedencias que asimismo aportan a la población tinerfeña, como es el caso de China, que se suma a la histórica presencia hindú, y de Senegal, a la de marroquíes. Con todo, las cinco procedencias más importantes suman más de cien mil efectivos en 2018, el 54,4\% de la población de origen extranjero, siendo por este orden, Venezuela, Italia, Cuba, Reino Unido y Alemania. Las diez siguientes agrupan solo una cuarta parte.

Venezuela e Italia vienen siendo los orígenes protagonistas en los últimos años, como ya se ha señalado, particularmente a partir de 2016 en el primer caso y de 2014 en el segun- 
do, como atestiguan las variaciones residenciales, cuyos saldos son más cuantiosos desde esas fechas. Ambas procedencias suman un tercio de la población de origen extranjero registrada en 2018, habiendo triplicado esa aportación desde 2001. Se trata, además, de las dos estructuras demográficas, tomando como referencia las cinco primeras procedencias nacionales, que menor grado de envejecimiento ofrecen: 0,51 en el caso venezolano y 1,47 en el italiano, considerando la diferencia entre la población de 65 y más años en relación con la menor de 15 .

\begin{tabular}{l|c|c|c|c|c}
\hline Países de origen & $\mathbf{2 0 0 1}$ & $\%$ & $\mathbf{2 0 1 8}$ & $\%$ & Tasa \\
\hline Venezuela & 16.746 & 23,9 & 42.586 & 22,9 & 5,64 \\
\hline Italia & 3.365 & 4,8 & 19.224 & 10,3 & 10,80 \\
\hline Cuba & 3.775 & 5,4 & 17.745 & 9,5 & 9,53 \\
\hline Reino Unido & 9.710 & 13,9 & 12.321 & 6,6 & 1,41 \\
\hline Alemania & 10.440 & 14,9 & 9.590 & 5,1 & $-0,50$ \\
\hline Colombia & 1.246 & 1,8 & 8.188 & 4,4 & 11,71 \\
\hline Argentina & 2.291 & 3,3 & 8.104 & 4,3 & 7,71 \\
\hline Marruecos & 2.265 & 3,2 & 5.656 & 3,0 & 5,53 \\
\hline Uruguay & 580 & 0,8 & 4.773 & 2,6 & 13,20 \\
\hline China & 765 & 1,1 & 3.832 & 2,1 & 9,94 \\
\hline Rumanía & 170 & 0,2 & 3.761 & 2,0 & 19,98 \\
\hline Francia & 2.597 & 3,7 & 3.490 & 1,9 & 1,75 \\
\hline Bélgica & 1.889 & 2,7 & 2.760 & 1,5 & 2,26 \\
\hline India & 1.610 & 2,3 & 2.404 & 1,3 & 2,39 \\
\hline Ecuador & 274 & 0,4 & 2.073 & 1,1 & 12,64 \\
\hline Total & $\mathbf{5 7 . 7 2 3}$ & 83,1 & 146.507 & 79,5 & 5,63 \\
\hline Tenerife & 69.924 & 100,0 & 186.354 & 100,0 & 5,94 \\
\hline
\end{tabular}

Tabla 1

Orígenes nacionales con más de dos mil efectivos en Tenerife en 2018 y su comparativa con 2001.

\section{Fuente}

Padrón Municipal de Habitantes, ISTAC.

Elaboración propia.

\section{Perfil sociodemográfico y pautas de asentamiento de los principales grupos de inmigración}

Los perfiles sociodemográficos de los principales grupos nacionales son bastante divergentes en la actualidad, resultado de la evolución de las distintas afluencias en los últimos años en que se han producido evidentes cambios, tanto en intensidades como en composición. Es palpable la feminización de la inmigración en términos generales, particularmente visible en el amplio colectivo americano, que registra una sex ratio de $84,9 \%$ en 2018 , siendo solo un poco más elevadas las observadas por venezolanos $(87,5 \%$ ) y cubanos $(87,2 \%)$. La estructura demográfica del primer grupo aparece con una silueta particular, en la que es minoritaria la población que ocupan los tramos de edades más avanzadas, reflejo de corrientes más recientes que sobre todo están aportando personas de mediana edad. 
Factsheet OBITen_05

Gráfico 3

Estructura demográfica

por sexo y edad de los cinco orígenes nacionales

con más efectivos en

Tenerife en 2018 (tantos

por mil).

Fuente

Padrón Municipal de

Habitantes, ISTAC.

Elaboración propia.
Estructura demográfica de la población de origen venezolano en Tenerife en 2018

95-99

$90-94$

$85-89$

80-84

$75-79$

$70-74$

$65-69$
$60-64$

55-59

50-54

45-49

$40-44$
$35-39$

30-34

25-29

$25-29$

$20-24$
$15-19$

$15-19$
$10-14$

$5-9$

$-80,0$

$-60,0$

$-40,0$

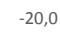

0,0

40,0

60,0

80,0

Mujeres -Hombres

Estructura demográfica de la población de origen italiano en Tenerife en 2018

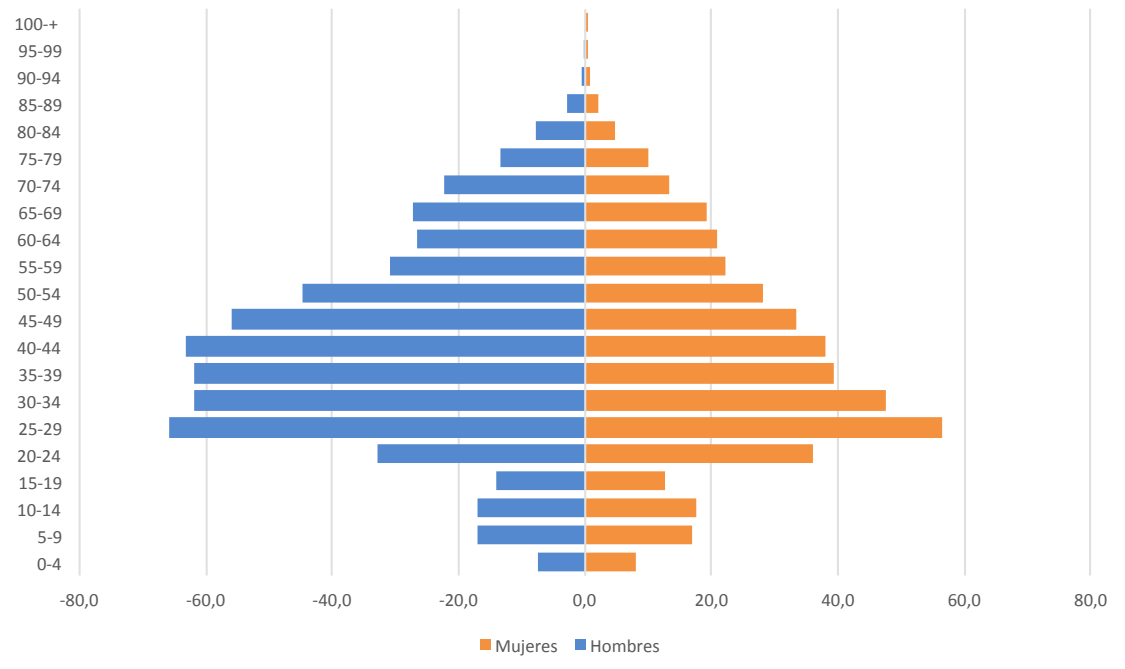

Estructura demográfica de la población de origen británico en Tenerife en 2018
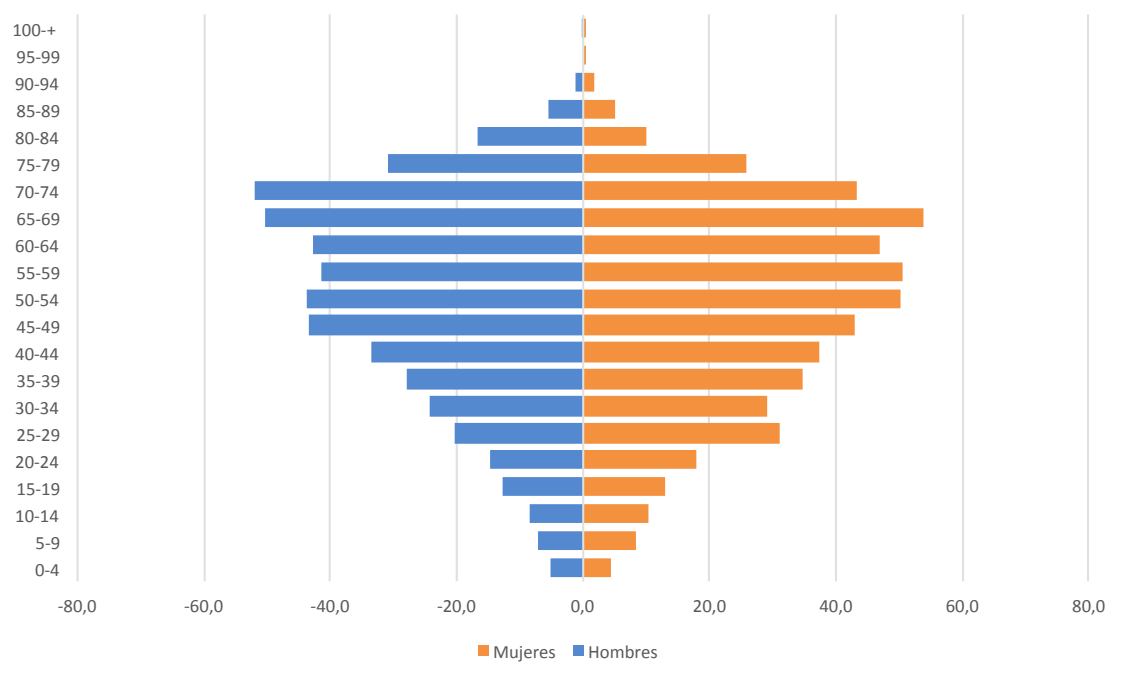

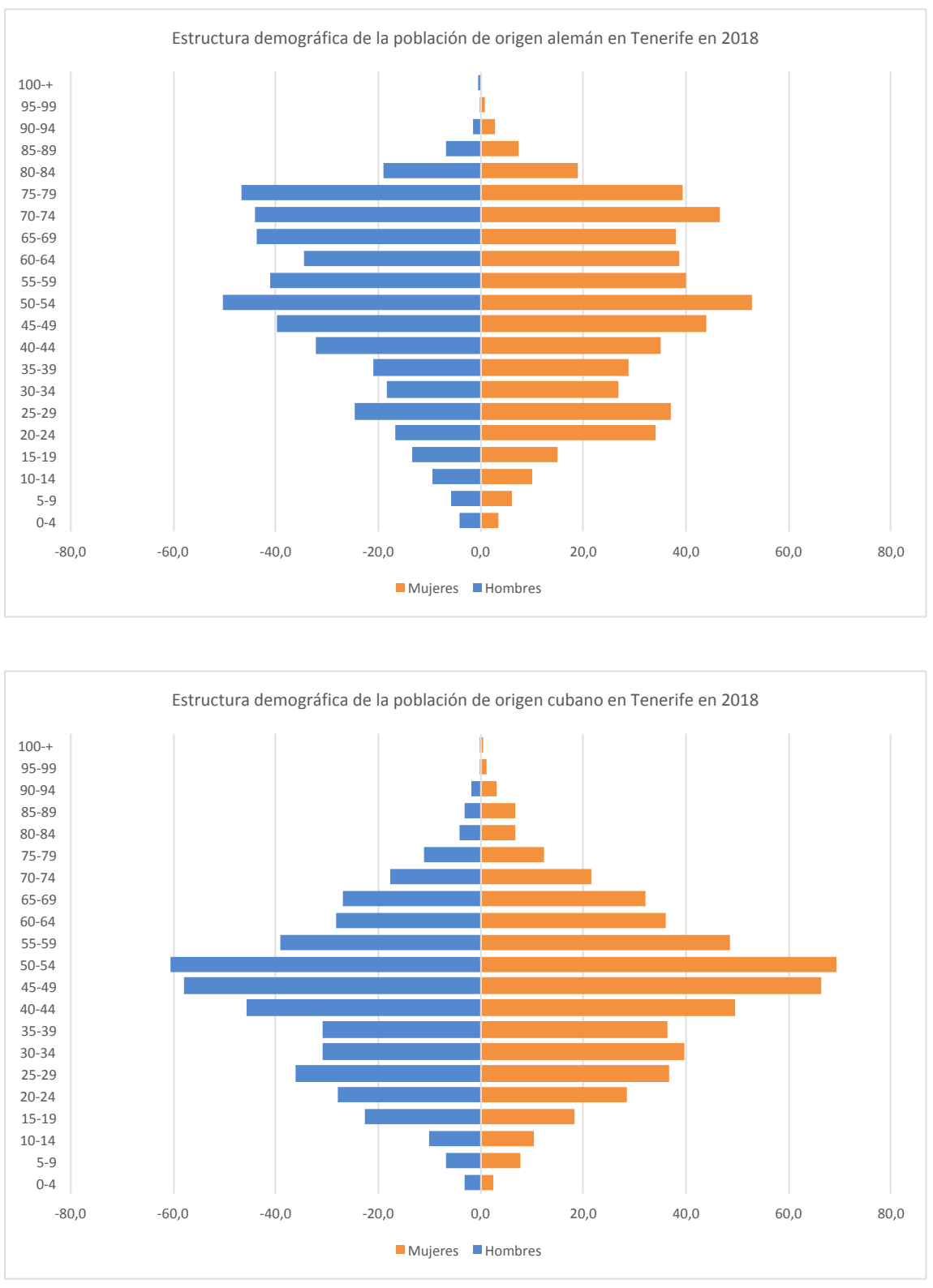

En efecto, la actual población venezolana en Tenerife tiene mayor perfil femenino (el $53,3 \%$ son mujeres) y concentra el $47,2 \%$ de sus efectivos entre 35 y 54 años en 2018 , siendo el colectivo de mayores o personas de 65 y más años bastante reducido, puesto que no alcanza las 1.500 y en esta misma franja es mucho más visible la presencia de mujeres (su índice de envejecimiento es el triple que el de los hombres). En contraposición encontramos la población de origen italiano, en su mayor parte masculina (57,3\%), todavía más desequilibrada que la venezolana según sexos, con una importante concentración en el segmento masculino entre 25 y 54 años (35,3\% de su empadronamiento) e índices de envejecimiento que superan la unidad, más pronunciado en hombres $(1,77$ frente a 1,17, relacionando la población vieja con la joven). Sus pirámides contrastan de manera notable.

En todo caso, las estructuras más envejecidas son las que ofrecen británicos y sobre todo alemanes, fruto de la incidencia del asentamiento residencial de personas de edades avanzadas y su repercusión en el ascenso de la mortalidad conforme pasa el tiempo. Eso implica índices altísimos, como el de los hombres de origen alemán: 8,43 en 2018. Su 
perfil demográfico es prácticamente el de una pirámide invertida. Un tercio de alemanes tiene 65 o más años y casi el $30 \%$ de británicos, en ambos casos según su origen. Dentro de estas irregularidades, la estructura cubana parece la más equilibrada según edades, aunque también con un alto grado de envejecimiento $(3,69 \%)$, mayor en el colectivo femenino, el preponderante además $(53,4 \%)$.

El ascenso de unas corrientes y el declive de otras, junto a la emergencia de más grupos nacionales de cierta relevancia, aparte de las cinco citadas, como puede ser el caso de colombianos y argentinos, en el colectivo americano, y marroquíes, chinos y rumanos, entre otros, ha ocasionado algunas variaciones en la distribución de la población de origen extranjero en Tenerife. Se ha reforzado así el poder de atracción de la vertiente meridional de la Isla, particularmente en el arco entre Santiago del Teide y Granadilla de Abona, donde ya reside el $52,4 \%$ de esta población en 2018, coincidiendo con la máxima concentración allí de habitantes de procedencia italiana (el 77,5\% se localiza en el Sur de Tenerife) y una fracción muy significativa de cubanos, convirtiéndose asimismo en la principal zona de residencia de británicos y uno de los centros de atención de la más reciente afluencia venezolana. Todo ello remarca el carácter económico-laboral de buena parte de este asentamiento, que se orienta hacia los mercados de trabajo más pujantes de la Isla y hacia uno de los espacios residenciales más atractivos.

Mapa 1

Distribución de la población de origen extranjero en Tenerife según entidades de población en 2017.

Fuente

Padrón Municipal de Habitantes, ISTAC. Elaboración propia.

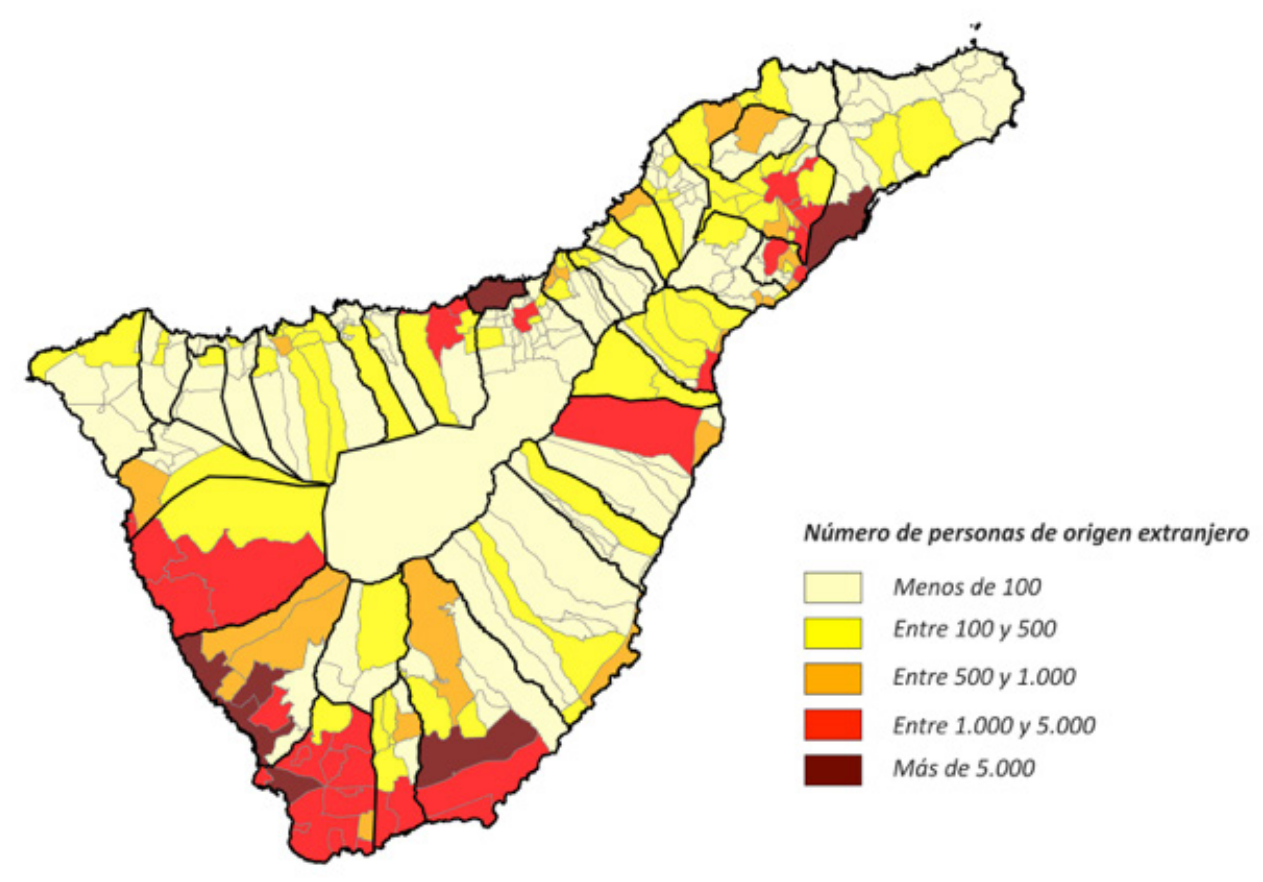

Por otra parte, destaca el mantenimiento del protagonismo anterior del Área Metropolitana, frente al enorme debilitamiento del asentamiento de población inmigrante en el Norte de Tenerife, que ha pasado del $28,6 \%$ al $14,5 \%$ de los efectivos de origen extranjero empadronados entre 2001 y 2018, perdiendo peso la población de las cinco primeras procedencias citadas, llamando incluso la atención la reducción de las cifras de británicos $(-3,12 \%$ anual) y alemanes $(-2,30 \%$ anual) entre las mismas fechas; la suma de sus efectivos se reduce en más de 2.500 personas. La reciente llegada de habitantes de naturaleza venezolana observa una inclinación hacia el asentamiento en el espacio capitalino, puesto que Santa Cruz de Tenerife y San Cristóbal de La Laguna agrupan el 42,1\% de estos habitantes en 2018, principal foco de su instalación insular, casi 18 mil efectivos. 


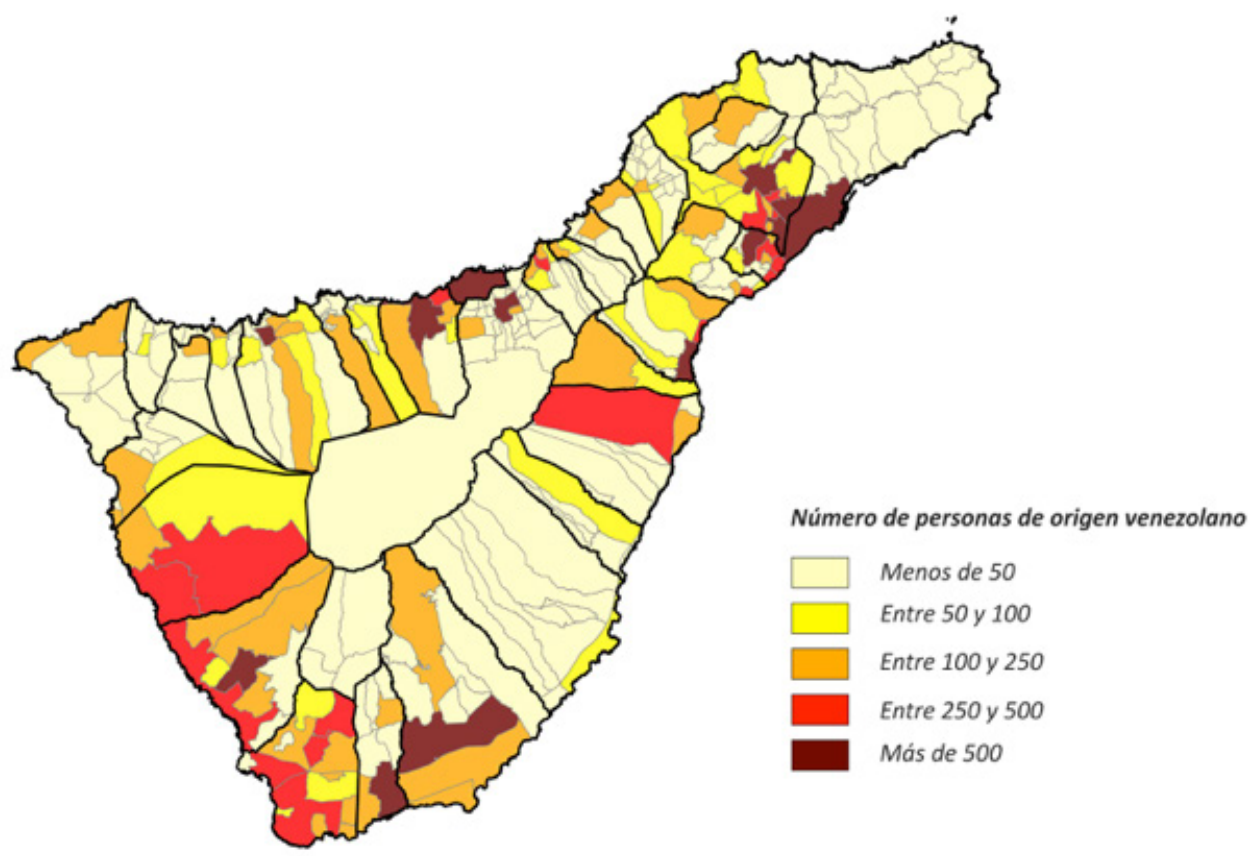

\section{Mapa 2}

Distribución de la población de origen venezolano en Tenerife según entidades de población en 2017.

\section{Fuente}

Padrón Municipal de Habitantes, ISTAC. Elaboración propia.

\section{Mapa 3}

Distribución de la población de origen italiano en Tenerife según entidades de población en 2017.

\section{Fuente}

Padrón Municipal de Habitantes, ISTAC.

Número de personas de origen italiano Elaboración propia.

Menos de 50

Entre 50 y 100

Entre 100 y 250

Entre 250 y 500

Más de 500

Las circunstancias apuntadas consolidan una dinámica geodemográfica que acentúa el fortalecimiento del asentamiento poblacional en el eje meridional de la Isla, entre el espacio capitalino y su arco occidental, que ha aumentado su relevancia, hasta registrar conjuntamente el 75,2\% del empadronamiento de 2018, debilitándose el corredor norteño al rebajar su peso en el contexto insular aunque globalmente no pierde habitantes. En esa franja meridional que arranca en la conurbación capitalina ahora viven casi 700 mil habitantes y el 85,5\% de la de origen extranjero, destacando asentamientos como Costa Adeje, San Isidro, Los Cristianos, Adeje, Las Chafiras, El Fraile, Costa del Silencio o Las Galletas, más hacia el Sur, y La Cuesta, el casco urbano de San Cristóbal de La Laguna, Taco y algunos barrios de Santa Cruz de Tenerife, en el espacio metropolitano. 


\section{Intensificación reciente de la inmigración de origen venezolano}

Como se ha destacado en los párrafos anteriores, la inmigración de origen venezolano, a pesar de su presencia constante en el panel de procedencias internacionales más relevantes de Tenerife (Zapata, 2002), representa una de las novedades más significativas por su notable incremento en los últimos cinco años. Este aumento refleja la importante aceleración de la emigración desde Venezuela que numerosas investigaciones vinculan directamente a la crisis social, económica y política que está atravesando ese país americano. Según diferentes informes internacionales, las condiciones de vida de la sociedad venezolana han empeorado sensiblemente en los últimos años: Venezuela tuvo en 2017 una recesión del 11,9\%, según los datos del Banco Mundial, destacando asimismo el Fondo Monetario Internacional que se trata del país con mayor inflación en el mundo (13,864\%).

Según la Encuesta Nacional de Condiciones de Vida (ENCOVI, 2017), los hogares en situación de pobreza han pasado del 48,4 al 87,0\% entre 2014 y 2017; y la pobreza severa ha aumentado hasta el 61,2\%. La misma encuesta subraya, también, los graves problemas relacionados con la escasez de medicamentos, la precariedad de los servicios públicos y los frecuentes cortes de luz y de agua. La Organización de las Naciones Unidas para la Alimentación y la Agricultura (FAO) señala que el 9,5\% de su población estaba subalimentada en 2018. Además de los factores económicos, destacan los problemas relacionados con la seguridad ciudadana: el Observatorio Venezolano de Violencia estima una tasa de 81,4 muertes violentas por cada 100.000 habitantes; el Observatorio Venezolano de Conflictualidad Social ha registrado 9.286 manifestaciones de protesta en 2017.

Todos estos elementos evidencian que, como subrayan Koechlin y Eguren (2018), no se pueda reducir la emigración venezolana a las dinámicas económicas, sino que se trata de un éxodo que tiene características de exilio o migración forzosa. Este aspecto es muy importante tenerlo en cuenta, porque afecta notablemente al proyecto migratorio de las personas migrantes. De hecho, los estudios sobre la inmigración de origen venezolano en España destacan el cambio de perfil del último lustro: de emigrantes económicos con un proyecto migratorio caracterizado por la búsqueda del mantenimiento o mejora del estatus social del país de origen, se ha pasado a una migración empujada por motivos de supervivencia que afecta a todas las clases sociales (Páez y Phélan, 2018). Además, por tercer año consecutivo, Venezuela ha sido el país de origen de un mayor número de personas solicitantes de protección internacional en España: 19.280 solicitudes presentadas en 2018 (el 35,0\% del total), frente a las 10.350 tramitadas en 2017 (CEAR, 2018), en Canarias se han registrado, en 2018, 1.438 solicitudes de personas de origen venezolano.

Según el estudio llevado a cabo por Bermúdez et al. (2018), el 72,3\% de las personas encuestadas indica que uno de los tres principales motivos de la decisión de emigrar es la inseguridad, el 70,8\% cita también la falta de perspectivas y el 63,1\% el hambre. En este sentido, Venezuela se ha transformado de gran país receptor de inmigrantes a protagonizar una de las más importantes crisis migratorias a escala mundial. Naciones Unidas estima que, desde 2014, más de 2,3 millones de personas han dejado Venezuela, una cifra que puede infraestimar los cruces fronterizos, sobre todo con Colombia (Human Rights Watch, 2018). Algunas investigaciones sobre las migraciones en Venezuela destacan que, en general, la sociedad venezolana no posee cultura migratoria, lo cual se traduce en la falta de solidas redes de apoyo en los países de acogida y la falta de proyectos migratorios (Castillo y Reguant, 2017; Bermúdez et al., 2018).

Si bien, históricamente, Venezuela no ha sido un país emisor de emigrantes, la emigración venezolana no es un fenómeno nuevo, sino un proceso que ha empezado a ser significa- 
tivo hace dos décadas y que se está acelerando en los últimos cinco años. De hecho, en una encuesta sobre la inmigración venezolana en Colombia se destaca que el 53,5\% de las personas encuestadas tiene algún familiar que le espera en Colombia y un $42,5 \%$ tiene amigos que les pueden ayudar (Bermúdez et al., 2018). Un estudio sobre estudiantes universitarios venezolanos destaca que el $88,1 \%$ de los estudiantes en universidades públicas en 2015 tiene intención de emigrar. El 80,0\% de los encuestados conoce a personas que se han ido en los últimos cinco años (De La Vega y Vargas, 2017).

Según los datos de la Organización Internacional de las Migraciones, los cuatro principales destinos de la emigración venezolana son, en orden de importancia, Colombia, Perú, Estados Unidos y España (OIM, 2018). En términos generales, el aumento de la inmigración de origen venezolano en España se explica por la facilidad del idioma, la cercanía cultural y por la posesión de la nacionalidad española de numerosos migrantes venezolanos (Castillo y Reguant, 2017); en el caso canario, además, un factor clave es la estrecha relación histórica entre Canarias y Venezuela, con un continuo flujo de ida y venida.

Y en ese contexto, Tenerife es la isla que concentra la mayor fracción de población de origen venezolano de Canarias, casi las tres cuartas partes del total (72,9\%), aproximándose a la cuarta parte de su población de naturaleza extranjera. En este último sentido, solo El Hierro $(51,1 \%)$ y La Palma $(30,5 \%)$ le superan y La Gomera se aproxima $(19,8 \%)$, pero con cifras absolutas muy inferiores. Los efectivos venezolanos de El Hierro suponen el 11,9\% de su población total, frente al $4,7 \%$ tinerfeño. En el marco regional y en todas las islas, el colectivo de venezolanas es más importante.

\section{¿Por qué las personas de origen venezolano han elegido Tenerife como destino?}

El Observatorio de la Inmigración de Tenerife ha llevado a cabo una encuesta online sobre los principales motivos por los cuales las personas inmigrantes de origen venezolano, llegadas desde 2014, han elegido la Isla como destino. La muestra estaba compuesta por 134 personas residentes en Tenerife desde el año 2014. El 65,7\% de la misma eran mujeres, el $48,5 \%$ tiene solo nacionalidad venezolana, el 5,2\% posee nacionalidad de otro país europeo (italiana o portuguesa) y el $46,3 \%$ tiene nacionalidad española. Con respecto a la edad, el $24,6 \%$ tiene entre 18 y 35 años, el $64,2 \%$ de 35 a 60 y el $11,2 \%$ es mayor de 60 años.

El primer aspecto a destacar es que, como se puede observar en la tabla III, casi el $80 \%$ de las personas encuestadas ha emigrado de Venezuela con algún miembro de su familia, y que, solamente, el $6 \%$, no conocía a nadie. Estos datos evidencian la existencia de una cadena migratoria basada en vínculos familiares y que ésta radica en la relación histórica de la migración entre Canarias y Venezuela.

\begin{tabular}{l|c}
\hline Con quién han emigrado & $\%$ \\
\hline Pareja e hijos/as & 32,8 \\
\hline Pareja & 26,1 \\
\hline Padres & 20,1 \\
\hline Solo/a & 19,4 \\
\hline Amigos/as & 1,5 \\
\hline Total & 100,0 \\
\hline
\end{tabular}

Tabla 2

Personas con las cuales ha llegado a Tenerife.

Fuente

Encuesta online a la población venezolana 2019, OBITen. Elaboración propia. 
Tabla 3

Conocimiento de personas que les ha informado o ayudado

en la primera fase

de asentamiento en

Tenerife.

Fuente

Encuesta online a la población venezolana 2019, OBITen.

Elaboración propia.

Tabla 4

Distribución de los tres principales motivos por los cuales las personas inmigrantes de origen venezolano han elegido Tenerife como destino.

Respuesta múltiple, máximo tres opciones.

Fuente

Encuesta online a la población venezolana 2019, OBITen.

Elaboración propia.

\begin{tabular}{l|c}
\hline Apoyo inicial & $\%$ \\
\hline Familiares & 76,9 \\
\hline Amigos & 17,2 \\
\hline No conocía a nadie & 6,0 \\
\hline Total & 100,0 \\
\hline
\end{tabular}

La importancia de las redes familiares se evidencia, también, en las motivaciones de elección de Tenerife: el 78,4\% afirma que uno de sus principales motivos ha sido tener familiares o amistades que viven en la Isla. La segunda motivación, elegida por más del 61,9\% de las personas encuestadas, destaca la tranquilidad y la seguridad, mientras que la tercera citada con mayor frecuencia es el clima $(26,1 \%)$.

\begin{tabular}{l|c}
\hline Motivos & $\%$ \\
\hline Familiares y/o amistades viven en Tenerife & 78,4 \\
\hline Tranquilidad y seguridad & 61,9 \\
\hline Clima & 26,1 \\
\hline Similitud cultural & 24,6 \\
\hline Tolerancia y apertura de la sociedad canaria & 20,9 \\
\hline Coste de la vida & 17,9 \\
\hline Búsqueda de empleo & 14,9 \\
\hline Oportunidades empresariales & 5,2 \\
\hline Vivir una experiencia en el extranjero & 3,0 \\
\hline Menor presión fiscal & 2,2 \\
\hline
\end{tabular}

\section{La diversidad de perfiles de la inmigración de origen italiano}

Contrariamente al caso de Venezuela, la emigración ha sido una constante en la historia italiana, caracterizada tanto por intensos flujos migratorios internos desde el Sur hacia el Norte y desde las zonas rurales hacia las urbanas, como por importantes migraciones hacia América y Europa (Sanfilippo, 2017). Según los datos de 2018 del AIRE, el registro civil de las personas italianas residentes en el exterior, 5.114 .469 personas de nacionalidad italiana residen fuera de Italia: 819.910 en Argentina; 415.887 en Brasil; 411.949 en Francia; 743.822 en Bélgica; 300.629 en Reino Unido; 265.733 en Estados Unidos; 214.900 en Suiza; y 164.384 en España, el 3,2\% del total. Sin embargo, la Fundación Migrantes (2018) evidencia que los países donde está aumentado mayormente el número de emigrantes italianos en los últimos años son Portugal, Brasil y España.

En los últimos cinco años el aumento de la emigración de origen italiano es del 14,0\%, pero los datos son seguramente superiores, porque, según numerosos expertos, el registro en el AIRE no es una práctica común entre las personas que han emigrado, sobre todo si residen en países europeos (Pugliese, 2015). Hay que tener en cuenta que los datos del AIRE incluye a las personas nacidas fuera de Italia y que tiene la nacionalidad italiana por ser descendiente de italianos. En este documento nos centramos en el análisis de la inmigración de origen y nacionalidad italiana. 
Diferentes estudios han evidenciado que a partir del nuevo milenio, y sobre todo con la crisis económica de 2008, ha empezado un nuevo ciclo de la emigración en Italia que se caracteriza por una mayor presencia de las mujeres, minoritarias en los ciclos anteriores. También el aumento de la emigración hacia nuevos destinos europeos como España, la procedencia urbana de las personas migrantes, frente a la mayor frecuencia del origen rural anterior, así como la diversificación de perfiles en relación con el predominio del emigrante económico (Pugliese, 2015).

Las causas principales de la emigración italiana más citadas en los estudios de este fenómeno son el desempleo, el empobrecimiento, el aumento de las desigualdades sociales, el coste de la vida y la falta de perspectivas. Este último aspecto es particularmente importante en el caso de la juventud, puesto que, como subraya Gjergji (2015), emigra no solo por motivos económicos, sino por un contexto cultural y político asfixiante, que no permite el desarrollo personal y social.

El principal periódico italiano, La Repubblica, ha recogido, desde 2001, más de 25.000 testimonios de emigrantes italianos en el extranjero. A partir de estos testimonios se puede destacar que la emigración de los jóvenes no se puede encuadrar solamente en el esquema de una "fuga de cerebros", como a menudo se refleja en los medios de comunicación italianos, sino que está relacionada, sobre todo, con la exclusión de las jóvenes generaciones del pacto social, de un proyecto social común (Allegri y Ciccarelli, 2011).

Un segundo perfil muy presente en la emigración hacia países donde el coste de la vida es más bajo, es el de familias que se desplazan con un proyecto vital y empresarial, normalmente vinculado a la restauración. En este caso, los factores que más pesan en la decisión de emigrar son el coste de la vida, la presión fiscal, la desconfianza hacia la política y la sociedad italiana.

Finalmente, sobre todo en países como España, República Checa y Portugal, se está desarrollado un flujo migratorio relativamente nuevo en el contexto de la emigración italiana, la denominada sun migration, es decir, el desplazamiento de personas jubiladas a regiones de Europa con mejor clima (Pugliese, 2015). Este fenómeno se explica, además, si se tienen en cuenta los acuerdos bilaterales que rebajan significativamente la presión fiscal: la mitad de las pensiones italianas pagadas en el extranjero en 2017 son de jubilados residentes en algún país europeo. Un aspecto sin duda interesante es que España - y en especial Tenerife- es un territorio en el que estas nuevas tendencias son particularmente evidentes.

España es sin duda el destino emergente en el panorama migratorio italiano. Los aspectos atractivos de determinadas zonas de España, en particular Madrid, Barcelona, Andalucía y Canarias, son el coste de la vida, de manera particular en las dos últimas, la cercanía cultural y lingüística, las oportunidades económicas y la percepción generalizada de una sociedad más abierta, progresista y dinámica con respecto a la italiana (Cucchiarato, 2010). Además, como subraya Ballatore (2017), en el caso de los jóvenes, hay que tener en cuenta la importancia de los programas de estancia en el extranjero como el Erasmus: España es el primer destino de estudiantes universitarios italianos y estas experiencias en el extranjero suelen desempeñar un papel clave en la decisión de emigrar.

Canarias y en particular Tenerife destacan en el panorama español por tener la mayor proporción de emigrantes de nacionalidad y de origen italiano. En el resto de España, sobre todo en Cataluña, el número de emigrantes de nacionalidad italiana pero de origen americano suele ser significativamente mayor. 
A principios de 2018 residían 45.430 personas de nacionalidad italiana en Canarias, de las cuales 36.626 han nacido en Italia $(80,6 \%)$. En Tenerife la proporción es parecida: residen 24.220 personas de nacionalidad italiana, de las cuales 19.224 nacieron en Italia $(79,3 \%)$. Esta proporción ha variado a lo largo de los últimos veinte años, pero no ha estado más por debajo del $60 \%$ (66,2\% en 2007). En el resto de España la proporción de inmigrantes de nacionalidad italiana de origen latinoamericano es mayor.

Tenerife es la isla en la cual reside un mayor número de personas de origen italiano: el $10,3 \%$ de los residentes extranjeros ha nacido en Italia. En el resto de las islas tanto los números absolutos como la proporción sobre el conjunto de efectivos de origen extranjero es menor, salvo en Fuerteventura, donde suponen el 16,7\%: en Lanzarote residen 2.935 italianos (6,7\% del total de extranjeros), en Fuerteventura 6.447, en Gran Canaria 7.328 (6,9\%), en La Gomera 142 (3,5\%), en La Palma 479 (3,4\%) y en El Hierro 73 (2,9\%). Sin embargo, en los último diez años, el mayor aumento relativo se ha registrado en Fuerteventura y Lanzarote, donde la presencia de italianos ha aumentado un $34 \%$ y un $27 \%$, respectivamente, frente al $203 \%$ de Tenerife. En todas las islas los hombres italianos son mayoritarios y en el conjunto regional suponen el $57,1 \%$ de este origen nacional.

La investigación sobre la emigración italiana reciente ha destacado que no se trata de un fenómeno que se puede reducir a los factores económicos, sobre todo en el caso español, y que los motivos varían sensiblemente según los diferentes perfiles de las personas que emigran (Lollo y García Pereiro, 2011).

\section{¿Por qué las personas de origen italiano han elegido Tenerife como destino?}

También en este caso el Observatorio de la Inmigración de Tenerife ha llevado a cabo una encuesta online, en italiano, con una muestra de 124 personas de origen italiano y de nacionalidad italiana, residentes en Tenerife desde el año 2014. El 45,2\% de la muestra eran mujeres, el 33,9\% se encuentra entre 18 y 35 años, el $50 \%$ tiene edades comprendidas entre 35 y 60 , y el 16,1\% es mayor de 60 años. Además, hay que destacar que el 33,9\% ha emigrado desde una región del norte de Italia, el $11,3 \%$ del centro y el $54,8 \%$ del sur.

Contrariamente a la inmigración de origen venezolano, la proporción de personas que han llegado a Tenerife solas es alta (37,9\%). Pero las diferencias son significativas según los grupos de edad: la mitad de las personas menores de 35 años han llegado solas, mientras que esta proporción desciende al $3 \%$ en el resto de las edades.

Tabla 5

Personas con las que ha llegado a Tenerife.

Fuente

Encuesta online a la población italiana 2019, OBITen.

Elaboración propia.

\begin{tabular}{l|c}
\hline Con quién han emigrado & $\%$ \\
\hline Solo/a & 37,9 \\
\hline Pareja & 33,1 \\
\hline Pareja e hijos/as & 25,3 \\
\hline Padres & 3,2 \\
\hline Amigos/as & 0,5 \\
\hline Total & 100,0 \\
\hline
\end{tabular}




\begin{tabular}{l|c}
\hline Apoyo inicial & $\%$ \\
\hline Amigos & 42,7 \\
\hline No conocía a nadie & 37,1 \\
\hline Familiares & 20,2 \\
\hline Total & 100,0 \\
\hline
\end{tabular}

Tabla 6

Conocimiento de personas que les ha informado o ayudado en la primera fase de asentamiento en la isla.

\section{Fuente}

Encuesta online a la

Solo una quinta parte de las personas inmigradas de origen italiano conocía a familiares, pero es llamativo que el 42,7\% conociera a amigos que le han podido informar o ayudar antes del viaje o en la primera etapa de asentamiento. En este caso también hay que destacar la existencia de una red de apoyo social y de una cadena migratoria, aunque no es de naturaleza familiar, sino basada en vínculos de amistad y de personas conocidas.

Con respecto a las motivaciones generales, las tres principales son las siguientes: el clima $(64,5 \%)$, el coste de la vida (56,5\%) y la tolerancia y apertura de la sociedad canaria (46\%). Si bien estos tres motivos son los más citados en los tres grupos edad, su peso especifico varía según perfil sociodemográfico. Las personas menores de 35 años citan con mayor frecuencia la tolerancia y apertura de la sociedad canaria, mientras que existe casi unanimidad entre los mayores de 60 años al elegir el clima como uno de los tres principales motivos.

\begin{tabular}{l|c|c|c|c}
\hline Principales motivos para elegir Tenerife & $\begin{array}{c}\text { De 18 a 35 } \\
\text { años }\end{array}$ & $\begin{array}{c}\text { De 36 a 60 } \\
\text { años }\end{array}$ & $\begin{array}{c}\text { Mayores } \\
\text { de 60 años }\end{array}$ & Total \\
\hline Clima & 38,1 & 56,5 & 95,0 & 64,5 \\
\hline Coste de la vida & 52,4 & 58,1 & 60,0 & 56,5 \\
\hline Tolerancia y apertura de la sociedad canaria & 71,9 & 53,2 & 40,0 & 46,0 \\
\hline Tranquilidad y seguridad & 23,8 & 35,5 & 65,0 & 36,3 \\
\hline Oportunidades empresariales & 19,0 & 43,5 & 20,0 & 31,5 \\
\hline Menor presión fiscal & 14,3 & 14,5 & 10,0 & 13,7 \\
\hline Vivir una experiencia en el extranjero & 28,6 & 6,5 & 0,0 & 12,9 \\
\hline Búsqueda de empleo & 21,4 & 8,1 & 0,0 & 11,3 \\
\hline Similaridad cultural & 16,7 & 8,1 & 5,0 & 10,5 \\
\hline Familiares y/o amistades viven en Tenerife & 11,9 & 8,1 & 5,0 & 8,9 \\
\hline
\end{tabular}

Estos resultados son coherentes con los obtenidos por los estudios presentados en las páginas anteriores. La inmigración de origen italiano que ha llegado en los últimos cinco años a Tenerife no constituye un colectivo homogéneo. Se pueden identificar al menos tres grupos con motivaciones diferentes: jóvenes, familias emprendedoras y personas jubiladas. Estos motivos evidencian que la inmigración italiana en Tenerife no se justifica ni solo por razones relacionadas con el clima, ni únicamente por motivos económicos, sino que pesa, sobre todo entre los jóvenes, un factor de atracción relacionado con la tolerancia y apertura de la sociedad canaria.
Tabla 7

Distribución según grupos de edad de los tres principales motivos por los cuales las personas inmigrantes de origen italiano han elegido Tenerife como destino (\%). Respuesta múltiple, máximo tres opciones.

\section{Fuente}

Encuesta online a la población italiana 2019, OBITen.

Elaboración propia. 


\section{Conclusiones}

Tenerife continúa sumando habitantes tras el corto periodo de pérdida de efectivos poblacionales debido principalmente a la crisis económica que incide en la merma inmigratoria, fenómeno que se ha ido recuperando en los últimos años, a causa, sobre todo, de la intensificación de la afluencia desde procedencias americanas como Venezuela y Cuba; también al cambio de protagonismo en las europeas, en las que Italia gana cada vez más terreno a las tradicionales Reino Unido y Alemania. De hecho, las personas residentes de ese último origen ahora son ligeramente menos que las que se encontraban empadronadas a comienzos de siglo. El peso de las naturalezas americanas es ahora más destacado, incidiendo asimismo en una mayor feminización de la inmigración.

La mayor repercusión de las motivaciones laborales, frente a las residenciales por ejemplo, hace que se refuerce el asentamiento de los nuevos habitantes en la franja meridional de la Isla, particularmente en el arco Suroeste. También influye en la diversificación de la inmigración y en la conformación de más localidades con un mayor componente multicultural, siendo entonces la convivencia un auténtico reto social en cada vez más lugares. En este aspecto ha influido la constatación de que, en el ascenso de las comunidades nacionales con más habitantes en Tenerife, han desempeñado un relevante papel las personas de su misma procedencia previamente instaladas, bien sean familiares o amistades. Y además, las circunstancias internas de países que están atravesando coyunturas favorables a la emigración, como pueden ser Venezuela o Italia.

A través del contacto directo con personas inmigrantes de ambas procedencias, mediante cuestionarios online, se han podido desentrañar buena parte de las motivaciones que han amplificado su repercusión en la Isla en los últimos años, con un perfil más diversificado en el caso de las personas de origen italiano, puesto que se liga desde proyectos empresariales y laborales hasta una migración meramente residencial. La grave situación venezolana y las históricas relaciones con el Archipiélago han incrementado este flujo hacia Canarias, siendo, en muchos casos, un desplazamiento no deseado que además está encontrando serías dificultades en cuanto a la inclusión sociolaboral de sus protagonistas en Tenerife, puesto que coincide con una etapa en la que se mantienen las estrecheces económicas para una parte muy significativa de sus habitantes. 
Para ampliar la información

Allegri, G. y Ciccarelli, R. (2011). La furia dei cervelli. Roma: Manifestolibri.

Ballatore, M. (2017). La mobilité étudiante en Europe. Une lente institutionnalisation sans réelle démocratisation. Hommes \& migrations, 1.317-1.318, 79-86.

Bermúdez, Y., Mazuera-Arias, R., Albornoz-Arias, N., Morffe Peraza, M.A. (2018). Informe sobre la movilidad humana venezolana. Realidades y perspectivas de quienes emigran. San Cristóbal: Venezuela: Servicio Jesuita a Refugiados (SJR).

Castillo Crasto, T. y Reguant Álvarez, M. (2017). Percepciones sobre la migración venezolana: causas, España como destino, expectativas de retorno. Migraciones. Publicación del Instituto Universitario de Estudios sobre Migraciones, (41), 133-163.

CEAR (2018). Informe CEAR 2019: Las personas refugiadas en España y Europa. Madrid: CEAR.

Cucchiarato, C. (2010). Vivo altrove. Giovani e senza radici: gli emigranti italiani di oggi. Milano: Bruno Mondadori.

De La Vega, I., y Vargas, C. (2017). La intención de emigración de estudiantes universitarios. Estudio comparado en cuatro universidades venezolanas. Interciencia, 42(12), 798-804.

ENCOVI (2017). Encuesta Nacional de Condiciones de Vida 2017 en Venezuela. Recuperado de: https://www.ucab.edu.ve/investigacion/centros-e-institutos-de-investigacion/encovi-2017/

European Commission EAC (2014). The Erasmus Impact Study. Effects of mobility on the skills and employability of students and the internationalisation of higher education. Brussels: European Commission.

FAO, FIDA, UNICEF, PMA y OMS (2018). El estado de la seguridad alimentaria y la nutrición en el mundo. Fomentando la resiliencia climática en aras de la seguridad alimentaria y la nutrición. Roma: FAO. Recuperado de: http://www.fao.org/3//9553ES/ i9553es.pdf.

FMI (2018). Perspectivas de la Economía Mundial. Informe Trimestral del Fondo Monetario Internacional, abril de 2018.

Fundación Migrantes (2018). Rapporto italiani nel mondo. Roma: Ediciones Tau.

Gjergji, I. (2015). Cause, mete e figure sociali della nuova emigrazione italiana. I. Gjergji (a cura di). La nuova emigrazione italiana, Venezia, Ca'Foscari, 17. Recuperado de:

http://www.imf.org/es/Publications/WEO/Issues/2018/03/20/world-economic-outlook-april-2018

Human Right Watch (2018). El éxodo venezolano. Human Right Watch. 
Koechlin J. y Eguren, J. (ed.) (2018). El éxodo venezolano: entre el exilio y la emigración. Madrid: Observatorio Iberoamericano sobre Movilidad Humana, Migraciones y Desarrollo.

Lollo, G. y García Pereiro, T (2011). Le componente della presenza italiana in Spagna. Rivista italiana di economia, demografia e statistica, LXV(3/4):133-140.

Observatorio Venezolano de Violencia (2018). Informe Anual de Violencia 2018. Recuperado de: https://observatoriodeviolencia.org.ve/ovv-lacso-informe-anual-de-violencia-2018/

OIM, Organización Internacional para las Migraciones. (2018). Tendencias migratorias en las Américas, República Bolivariana de Venezuela (Reporte Julio 2018). Recuperado de: https://robuenosaires.iom.int/

OVCS, Observatorio Venezolano de Conflictividad Social (2017). Conflictividad social en Venezuela en 2017. Recuperado de: https://www.observatoriodeconflictos.org.ve/ tendencias-de-la-conflictividad/informe-conflictividad-social-en-venezuela-en-2017.

Páez, T., y Phélan, M. (2018). Emigración venezolana hacia España en tiempos de revolución bolivariana (1998-2017). Revista Internacional de Estudios Migratorios (RIEM), 8(2), 319-355.

Pugliese, E. (2015). Le nuove migrazioni italiane: il contesto ei protagonisti. La nuova migrazione italiana. Cause, mete e figure sociali, 25-38.

Sanfilippo, M. (2017). La nuova emigrazione italiana (2000-2017): il quadro storico e storiografico. Studi Emigrazione, 54 (207), 359-378.

Zapata Hernández, V.M. (2002). La inmigración extranjera en Tenerife. Santa Cruz de Tenerife: Área de Desarrollo Económico del Cabildo Insular de Tenerife.

Cómo citar este artículo:

Cómo citar este artículo:Buraschi, D. y Zapata Hernández, V.M. (2019). Nuevas tendencias de la inmigración en Tenerife. OBITen Factsheet 5-2019. Recuperado de www.obiten.net.

https://doi.org/10.25145/r.obitfact.2019.12

El Observatorio de la Inmigración de Tenerife es una iniciativa conjunta del Cabildo de Tenerife y la Universidad de La Laguna que surge con vocación de estructura permanente y dinámica para avanzar en el conocimiento científico de los movimientos migratorios. OBITen desarrolla su actividad a modo de centro de recopilación, producción y difusión de información que facilita la opinión cualificada y favorece la toma de decisiones que redunden en una mejor gestión del fenómeno inmigratorio y sus implicaciones.

http://www.obiten.net 

